Article

\title{
Evaluation of an Empirical Reservoir Shape Function to Define Sediment Distributions in Small Reservoirs
}

\section{Bogusław Michalec}

Department Water Engineering and Geotechnics, Agriculture University, Al. A. Mickiewicza 24/28, Cracow 30-059, Poland; E-Mail: rmmichbo@cyf-kr.edu.pl; Tel.: +48-12-662-4052

Academic Editor: Clelia Marti

Received: 6 May 2015 / Accepted: 24 July 2015 / Published: 12 August 2015

\begin{abstract}
Understanding and defining the spatial distribution of sediment deposited in reservoirs is essential not only at the design stage but also during the operation. The majority of research concerns the distribution of sediment deposition in medium and large water reservoirs. Most empirical methods do not provide satisfactory results when applied to the determination of sediment deposition in small reservoirs. Small reservoir's volumes do not exceed $5 \times 10^{6} \mathrm{~m}^{3}$ and their capacity-inflow ratio is less than $10 \%$. Long-term silting measurements of three small reservoirs were used to evaluate the method described by Rahmanian and Banihashemi for predicting sediment distributions in small reservoirs. Rahmanian and Banihashemi stated that their model of distribution of sediment deposition in water reservoir works well for a long duration operation. In the presented study, the silting rate was used in order to determine the long duration operation. Silting rate is a quotient of volume of the sediment deposited in the reservoir and its original volume. It was stated that when the silting rate had reached 50\%, the sediment deposition in the reservoir may be described by an empirical reservoir depth shape function (RDSF).
\end{abstract}

Keywords: small reservoir; silting rate; silting forecast; sediment distribution

\section{Introduction}

The economic importance of small reservoirs depends largely on their capacity to store water. Due to the process of silting, the capacity of small reservoirs is reduced in a relatively short period of time [1,2]. Silting of reservoirs limits their proper operation. Due to the reduced volume, a reservoir cannot function in accordance with the design assumptions. Hartung [3] reported that a reservoir no longer 
complies with its functions when it is silted in $80 \%$. According to Pitt and Thompson [4], the reservoir is out of operation when $50 \%$ of the reservoir storage is filled with sediment. Therefore, it is important to obtain information on the lifetime of the existing or designed reservoir. This enables planning of renovations involving, among other things, the reservoir dredging, which allows for the rational reservoir operation. This in particular applies to small reservoirs are intensively silted in relatively short time. The main criterion of reservoirs' division is their volume [5]. In Poland [6] and in Romania [7] small reservoirs are described as water bodies of volume below $5 \times 10^{6} \mathrm{~m}^{3}$. Michalec [1] suggested a different method of classifying water bodies. After investigating the silting process of 12 water reservoirs with a volume of 23 to 3860 thousand $\mathrm{m}^{3}$, Michalec [1] showed that regardless of the generally accepted classification of dammed reservoirs due to their volume and damming height, they may be classified using the capacity-inflow ratio. The capacity-inflow ratio (C-I) is defined as the ratio between the reservoir volume and the total annual water supply. In small water bodies, Michalec's [1] values of this ratio ranged from $0.13 \%$ to $9.64 \%$. According to the proposed criterion, small reservoirs include those whose capacity-inflow ratio is less than $10 \%$.

A particularly important aspect of the analysis and evaluation of silting process is to determine the sediment distribution in the reservoir. Determination of the sediment distribution in the reservoir bottom is of particular importance, among others, to ensure the proper water intake operation. The understanding of sediment distribution allows for proper evaluation of investment efficiency, correct location of outlet equipment or water intakes. A number of empirical methods have been developed for determining the spatial distribution of sediment in reservoirs. Most of these methods have been developed based on medium and large reservoirs and cannot be applied due to the constrains of the capacity of small reservoirs. Those are among others methods: Borland and Miller's [8], Lara's [9], Strand and Pemberton's [10], Szechowycz and Qureshi's [11], Borland's [12], Garde et al. [13], Croley et al. [14]. The last three methods have been developed for the calculation of sediments deposited in a typical delta. On the other hand, Rooseboom and Annandale [15], or Annandale [16] based on the theory of minimum stream energy, developed the method for predicting the deltoid sediment distribution in large water reservoirs in Africa. However, as shown by Michalec [1] in several small water reservoirs in Poland, mostly small-fraction debris is deposited on the entire length of the reservoir, without creating deltoid formations. The obtained positive results of calibration of the Annandale [16] method, allowing for its application to predict the sediment distribution in small reservoirs, as well as the impossibility to use the above mentioned methods, led to the attempt to apply the method presented by Rahmanian and Banihashemi [17]. Application of these models for predicting the distribution of sediments in small reservoirs, with a volume of several million $\mathrm{m}^{3}$, is often impossible because these models were elaborated based on the results of silting measurements conducted in large and medium reservoirs.

The application of the Rahmanian and Banihashemi method [17] to predict the sediment distribution in small reservoirs has practical importance, as previously developed empirical methods cannot be applied in small reservoirs. There is a simple reason for the limited or lack of their applicability. Because of their size, the analysis of small reservoirs' silting allows for precise field measurements, which may be compared to the measurements performed on small-scale physical models. The results obtained from the land surveying and bathymetric measurements may provide data to allow for verification of theoretical methods and for development of empirical methods to describe the process of silting. The objective of this research was to use long-term silting measurements of three small reservoirs to apply the method 
presented by Rahmanian and Banihashemi [17] to forecast the sediment distribution in a small reservoir. Rahmanian and Banihashemi verified their proposed method based on large Iranian reservoirs with volumes from 33 to $3480 \times 10^{6} \mathrm{~m}^{3}$. According to the authors of this method, sediment deposition is predicted for a long term of operation. Rahmanian and Banihashemi [17] did not define the method of long duration operation forecasting. However, they verified this method based on silting measurements of reservoirs with volume of more than several cubic meters, classified as medium and large water bodies according to the criterion of Lara and Pemberton [18]. Due to varied silting rates of large, average and small reservoirs, the precise definition of the long duration operation, after which we will receive the results of calculations predicting the sediment distribution corresponding to the actual state, is extremely difficult. Therefore, to obtain reliable results of the sediment deposition forecast using the Rahmanian's and Banihashemi's method, we need the precise definition of long duration operation. It can be defined based on studies of operated reservoirs. The results of long-term silting measurements of small reservoirs formed the basis to define the long duration operation. By analyzing the curves of vertical sediment distribution, developed based on the measurements in different years of operation, the extent of reservoir silting to which the Rahmanian's and Banihashemi's empirical reservoir shape function was determined.

\section{Study Area}

The studied reservoirs are located in the Upper Vistula basin (Figure 1). They are classified as small water reservoirs, with a volume, according to the Polish criteria, below $5 \times 10^{6} \mathrm{~m}^{3}$.

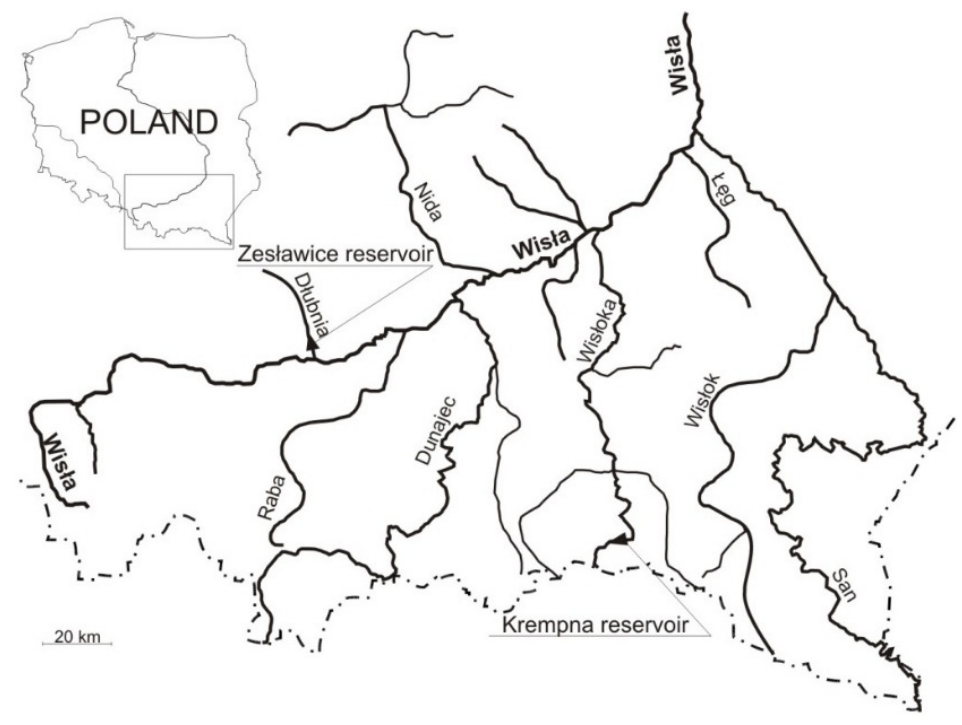

Figure 1. Location of the analyzed reservoirs.

In 1964-1966, small retention reservoir was built in Zesławice near Kraków, on the river Dłubnia. This reservoir, with a volume of 228 thousand $\mathrm{m}^{3}$, was designed to supply industrial water to the previous Vladimir Lenin's Steelworks. After 17 years of operation, 50\% of the Zesławice reservoir was silted. Before dredging, an assistant side reservoir had been constructed, which is referred to as Zesławice II. The main dredged reservoir, is referred to as Zesławice I. The construction of the assistant reservoir began in 1986 and in 1987 it was put into operation (Figure 2a). The assistant reservoir Zesławice II was designed to take over the functions of the main reservoir Zesławice I. This solution ensured the maintenance 
of damming and water uptake during dredging of the main reservoir in 1989. The Zesławice II reservoir was placed on the left bank of the river. Its initial volume was 198 thousand $\mathrm{m}^{3}$. Regular damming level of both reservoirs is $215.00 \mathrm{~m}$ a.s.1. Water surface area of the main and assistant reservoir at this damming level equals 9.50 and $11.3 \mathrm{ha}$, respectively, while the average depth is $2.4 \mathrm{~m}$ for the main reservoir and $1.75 \mathrm{~m}$ for the assistant reservoir [19].

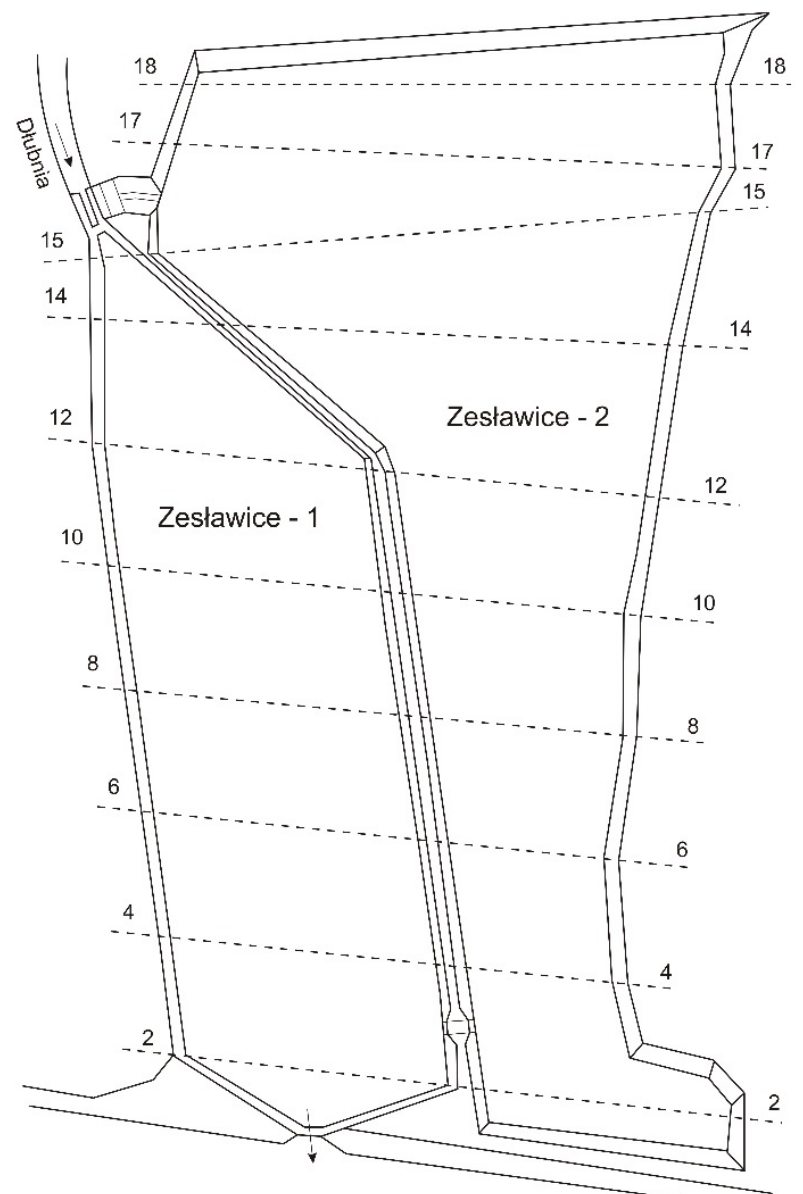

(a)

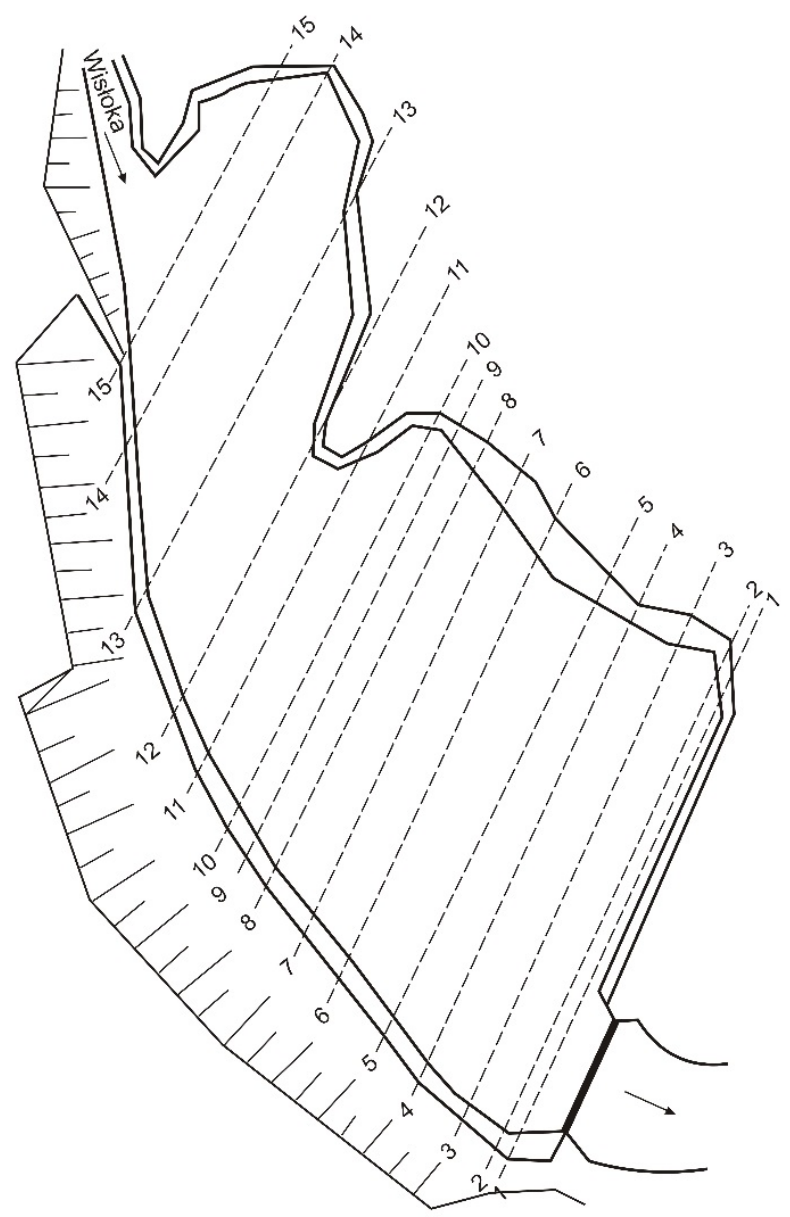

(b)

Figure 2. Reservoirs: (a) in Zesławice and (b) in Krempna. Cross-sections are marked in figures.

Surface of the river Dłubnia catchment is built from very strongly eroded surface formed from a layer of loess $15 \mathrm{~m}$ deep. A rather poor forest overgrowth of the catchment covering only $9.5 \%$ is not conducive to effective water retention in the catchment. In consequence of the dominating agricultural utilization $(80 \%)$ and system of development of the catchment, where arable land adjoins simply the flows great amounts of fine grained mineral material is carried away from the catchment. This has a very negative influence on water conditions in this territory: it accelerates the surface run off, hence, erosion of soil.

Small reservoir Krempna (Figure 2b), with an initial volume of 119 thousand $\mathrm{m}^{3}$, was constructed between 1970 and 1972. It was built to collect water in order to cover the domestic needs and for agricultural land irrigation. This reservoir was built as a water source that, as a consequence of rapid silting, was out of operation in 1980 and finally closed down during the reservoir dredging and reconstruction in 1987. As a result of this work, its initial volume was reduced to 112 thousands $\mathrm{m}^{3}$. Water surface of the reservoir remained unchanged at the level of $3.2 \mathrm{ha}$. The average depth of the reservoir before dredging 
was $3.72 \mathrm{~m}$ and after dredging- $3.5 \mathrm{~m}$. This reservoir serves as recreation and is supposed to capture a part of sediment to protect the designed large reservoir, with a volume of $150 \times 10^{6} \mathrm{~m}^{3}$, from silting.

The catchment area of the river Wisłoka confines the area with mountain and submontane relief. The superficial structures consists of the waste-mantle resulted from physical weathering like waste-clays and mountainside-clays, resting in the site their formation, and turned into loams and silty clays. In the river basin have been observed erosional landslides caused by fluvial erosion: caving mountainsides, heavy rains and the human activity (tree clearance, overcutting). Intensive forest husbandry supported the greater surface wash and many forest roads and lanes, which were deeply incised in hillsides, drained substantial part of catchment area. It has substantial impact on shaping the peak of storm runoff and the same on amount of load washed out into the river Wisłoka.

The reservoirs selected for the verification of the Rahmanian and Banihashemi method are located in the catchments, which vary in terms of physiographic conditions and their land use (Table 1 [1]). This has an impact on the intensity of erosion and sedimentation conditions of debris in the examined reservoirs.

Table 1. The selected basic parameters of the catchments.

\begin{tabular}{|c|c|c|c|c|c|c|}
\hline \multirow{2}{*}{ Reservoir } & \multirow{2}{*}{$\begin{array}{c}\text { Catchment Area } \\
\qquad \mathbf{W}\left(\mathbf{k m}^{2}\right)\end{array}$} & \multicolumn{4}{|c|}{ Land Use of Catchment } & \multirow{2}{*}{$\begin{array}{l}\text { Length of the River } \\
\text { from Spring to the } \\
\text { Reservoir Dam (km) }\end{array}$} \\
\hline & & Arable Land (\%) & Meadows (\%) & Forests (\%) & Other $(\%)$ & \\
\hline Zesławice & 218.0 & 78.1 & 1.6 & 9.5 & 10.8 & 44.5 \\
\hline Krempna & 163.3 & 4.0 & 2.0 & 80.1 & 1.9 & 18.6 \\
\hline
\end{tabular}

The elevation of the highest point in the catchment of the Dłubnia river (Zesławice reservoir) is $462 \mathrm{~m}$ a.s.1., while in the catchment of the Wisłoka river (Krempna reservoir) it is $780 \mathrm{~m}$ a.s.l. On the other hand, the elevation of the bottom of the reservoirs in the section in front of the dam is $211.60 \mathrm{~m}$ a.s.1. in the reservoir Zesławice and $366.28 \mathrm{~m}$ a.s.1. in the reservoir Krempna. The flows with a determined probability, calculated based on the data from the Institute of Meteorology and Water Management are presented in Table 2 [1]. The average annual inflow, determined based on the multi-annual data obtained from the Institute of Meteorology and Water Management reaches $1.09 \mathrm{~m}^{3} \mathrm{~s}^{-1}$ for the reservoir Zesławice before dredging and $2.03 \mathrm{~m}^{3} \mathrm{~s}^{-1}$ for the reservoir Krempna. The average annual inflow for the reservoir Zesławice was calculated for data collected from 1966 to 2003, and for data collected from 1972 to 2005 the average annual inflow was calculated for the reservoir Krempna.

Table 2. The selected basic parameters of the catchments.

\begin{tabular}{|c|c|c|c|c|c|c|c|}
\hline \multirow[t]{2}{*}{ Reservoir } & \multicolumn{3}{|c|}{ Probable Flows } & \multirow{2}{*}{$\begin{array}{l}\text { Sediment Delivery } \\
\text { Ratio SDR (-) }\end{array}$} & \multirow{2}{*}{$\begin{array}{c}\text { The Annual Mean } \\
\text { Mass of Erosion } \\
\text { Products acc. to USLE }\end{array}$} & \multicolumn{2}{|c|}{$\begin{array}{l}\text { The Mean Annual Mass of Delivered Suspended } \\
\text { Sediment }\left(10^{3} \text { tyear }^{-1}\right)\end{array}$} \\
\hline & $50 \%$ & $10 \%$ & $1 \%$ & & & acc. to SDR-USLE & acc. to Measurements \\
\hline Zesławice & 10 & 51 & 122 & 0.101 & 149,280 & 15.08 & 19.98 \\
\hline Krempna & 8 & 58 & 330 & 0.115 & 50,115 & 5.7 & 6.27 \\
\hline
\end{tabular}

The calculated annual mean sediment transport intensities, flowing into the examined reservoirs, are presented in Table 2 [1]. The mean annual mass of sediment flowing into the reservoirs was calculated based on the measurements of sediment concentrations in the water gauge sections. For this purpose, the products of mean daily flow and concentration, and then the mean daily sediment transport were 
calculated. The calculations were conducted by using the observation sequence of mean daily flows from the period of 1966-2003 (Dłubnia) and from 1972 to 2005 (Wisłoka). The mass of suspended sediment transported by rivers was determined on the basis of hydrological measurements of mean daily water discharge $(Q)$ and corresponding concentrations of suspended sediment $(P)$. Discharge values were supplied by measuring points of the Institute of Meteorology and Water Management. Measurements of suspended sediment concentrations in measuring profiles situated above the reservoirs were conducted using a Portable Suspend Solids and Turbidity Monitor System 770 (Partech). Available data sequences concerned water discharges for the whole period of individual reservoirs operation. Accessible data sequences of concentration values comprised shorter and random periods. Hydrological data sequences on discharge and concentrations were supplemented. For this reason function dependencies- $P=f(Q)$ - of mean daily discharges $(Q)$ and corresponding concentrations of suspended load $(P)$ were developed. The dependencies made possible supplementing the missing data for days omitted in the concentration measurements. Ratios of mean daily discharges to concentration were calculated and subsequently a mean daily sediment transport. Computations of sediment transport considered sediment concentration over the whole river cross-section. The mass of suspended load carried into each water reservoir was calculated for periods from the day of reservoir putting into operation till the day when the last measurement of silting was conducted.

The heterogeneity of hydrological data concerning measurements of water flow in gauging station was studied by applying a non-parametric Kruskal-Wallis rank-sum test [20]. The calculations of the suspended sediment transport were conducted taking into account the sediment concentration in the entire cross section of the river. In order to do this, the correction factor was determined, being the quotient of the mean concentration of suspended sediment in the cross-profile of the river and the concentration of the suspended sediment at the site of constant sampling [1]. Mean annual unit sediment runoff from the catchment of the Zesławice reservoir, calculated based on the measurements, reaches $91.6 \mathrm{t} \cdot \mathrm{km}^{-2}$.year ${ }^{-1}$, while from the reservoir Krempna it equals $38.4 \mathrm{t} \cdot \mathrm{km}^{-2} \cdot \mathrm{year}^{-1}$. Such a significant difference unit of sediment runoff due to the intensity of erosion in the loess catchment area of the reservoir Zesławice, which is almost $80 \%$, is used for agriculture. In contrast, more than $80 \%$ of the catchment of the Krempna reservoir is covered by forests. However, these are not high sediment yield values. This values are similar to those found for 17 catchments in northern Thailand, whose area can be classified as a tropical rainforest with high biodiversity and annual sediment transport varying from 18 to $216 \mathrm{t} \cdot \mathrm{km}^{-2} \cdot \mathrm{year}^{-1}$ [21]. The erosion rate of studied reservoirs is lower than mean erosion rate established for reservoirs in a semi-arid area in the southeast of Spain [22]. According to studies of Romero-Diaz et al. [22], a mean erosion rate calculated from 195 dikes equals to $3.95 \mathrm{t} \cdot \mathrm{ha}^{-1} \cdot \mathrm{year}^{-1}\left(395 \mathrm{t} \cdot \mathrm{km}^{-2} \cdot \mathrm{year}^{-1}\right)$. Lima Neto et al. [23] found that the total sediment yield in a large semi-arid Brazilian basin is about $148 \mathrm{t} \cdot \mathrm{km}^{-2}$.year ${ }^{-1}$. According to Jebari et al. [24] the average soil loss for small semi-arid Tunisian catchments is $14.5 \mathrm{t} \cdot \mathrm{year}^{-1} \cdot \mathrm{ha}^{-1}$ $\left(14,500 \mathrm{t} \cdot \mathrm{km}^{-2} \cdot \mathrm{year}^{-1}\right)$.

\section{Method of Study}

Sediment deposition volumes were determines from surveying. Based on these measurements bottom ordinates changes in cross-sections were determined as well as control points outside of sections. The measurements were performed with a rod probe from a boat, due to small depth of water bodies - the maximum depth of the reservoir Zesławice-1 is $3.3 \mathrm{~m}$, Zesławice-2-2.7 $\mathrm{m}$, and the maximum depth of 
the reservoir at Krempna equals to $3.5 \mathrm{~m}$. The measurement results were plotted on cross-sections and subsequently the area changes were identified in these sections. A change of a cross-sectional area corresponded to the deposition or erosion of bed material. Then the deposited sediment areas in cross-sections and volume of deposited sediments in the reservoir were calculated. The measurement accuracy of bottom elevation was $\pm 3 \mathrm{~cm}$ implied by ability to sink properly the foot of rod probe in sediment. According to Rausch and Heinemann [25] the measurements of changes in bottom height should be made with an accuracy of $\pm 3 \mathrm{~cm}$. The measurements of both the reservoir Zesławice- 1 and the reservoir Krempna after dredging were performed with a group of students, while the results of silting measurements of the reservoir Zesławice-1 and the reservoir Krempna before dredging were adopted from the paper of Bednarczyk and Lubowiecka [26], the initiators of the measurement cycle of small reservoirs' silting. All surveys were performed with the same equipment and in accordance with the agreed method of measurements.

The silting degree was calculated for a year of operation, in which silting measurements were performed. The temporal variability of silting rates for Zesławice reservoirs was characterized according to a theory of analyses of mass phenomena dynamics [27], performed on the basis of time series, described as dynamic or chronological. For this purpose, the correlations between silting rates and operating times were developed. Resulting curves were predicting the reduction of the analyzed reservoirs' volume, which allowed us to determine the operating time, after which the reservoirs cannot perform their functions due to being silted up. The calculations were carried out using the criterion of Pitt and Thompson [4], according to which the reservoir silted up by 50\% may no longer function as assumed in the project and often with such silting rate it is necessary to perform dredging works.

Correlations between silting rates and operating times allow to determine not only the time after which the reservoirs' volume will be reduced by $50 \%$ and $80 \%$, according to the criteria of Hartung [3] and Pitt and Thompson [4], respectively, but also allow to define the so-called long duration operation, which is an essential criterion for application of the Rahmanian's and Banihashemi's method. According to these authors, predictions of the relative cumulative sedimentation in a reservoir after long term of operation consists of the following steps [17]:

1. Drawing of initial relative volume-depth curve of a reservoir. This curve is drawn according to the function $h_{i} / H=f\left(V_{i} / V\right)$, where: $\mathrm{h}_{\mathrm{i}} / \mathrm{H}$ is the relative depth and $V_{i} / V$ is the relative volume.

2. For a long duration operation, the relative volume divided by the relative level gives relative cumulative sediment volume concept for each point on relative curve of volume-depth, where Relative Depth Shape Function (RDSF) is related to cumulative sediment deposition in different heights from reservoir bed. One can describe this in the form:

$$
(\operatorname{RDSF})_{\mathrm{i}}=\left(\frac{V_{i}}{V}\right) \times\left(\frac{H}{h_{i}}\right)=\left(\frac{V_{i}}{V}\right) \times\left(\frac{1}{\alpha_{\mathrm{i}}}\right)
$$

where:

$$
\alpha_{\mathrm{i}}=\left(\frac{h_{i}}{H}\right)
$$

The vertical distribution of sediments in the studied reservoirs was evaluated for each measurement by compiling the relative depth $\left(h_{i} / H\right)$-relative volume $\left(V_{i} / V\right)$ graphs. The curves were compared with 
Relative Depth Shape Function for different heights from reservoir bed (Equation (1)), defining the silting rate, for which the sediment distribution curves, developed on the basis of the measurement with the predicted curve, were the most compatible. The silting rate (S) was calculated as a quotient of volume of the sediment deposited in the reservoir $\left(\mathrm{V}_{\text {dep }}\right)$ and its original volume $\left(\mathrm{V}_{\text {res }}\right)$.

\section{Results and Discussion}

The measurement results of the sediment deposited at reservoir Zesławice-1, before and after dredging, and at Zesławice-2 are presented in Table 3. Calculations of silting rate of the studied reservoirs in different years of operation were based on the defined volume of sediment deposition.

Table 3. The silting rate and volume of sediments deposited in main and assistant reservoirs at Zesławice.

\begin{tabular}{|c|c|c|c|c|}
\hline Reservoir & Year & Years of Operations & $\begin{array}{c}\text { Volume of Deposited } \\
\text { Sediment }\left(10^{3} \mathrm{~m}^{3}\right)\end{array}$ & $\begin{array}{c}\text { Silting Ratio S } \\
(\%)\end{array}$ \\
\hline \multirow{16}{*}{$\begin{array}{c}\text { Main } \\
\text { (Zesławice-1) }\end{array}$} & 1968 & 2 & 27.0 & 11.8 \\
\hline & 1969 & 3 & 70.4 & 30.9 \\
\hline & 1970 & 4 & 75.8 & 33.2 \\
\hline & 1971 & 5 & 76.2 & 33.4 \\
\hline & 1974 & 8 & 86.3 & 37.8 \\
\hline & 1983 & 17 & 116.1 & 50.9 \\
\hline & 1989 & 23 & 140.2 & 61.5 \\
\hline & 1999 & 10 & 56.2 & 24.6 \\
\hline & 2005 & 16 & 75.3 & 33.0 \\
\hline & 2006 & 17 & 77.2 & 33.9 \\
\hline & 2008 & 19 & 81.5 & 35.7 \\
\hline & 2009 & 20 & 82.6 & 36.2 \\
\hline & 2010 & 21 & 97.6 & 42.8 \\
\hline & 2011 & 22 & 99.9 & 43.8 \\
\hline & 2012 & 23 & 108.0 & 47.4 \\
\hline & 2013 & 24 & 112.4 & 49.3 \\
\hline \multirow{8}{*}{ Assistant (Zesławice-2) } & 2005 & 18 & 37.2 & 18.8 \\
\hline & 2006 & 19 & 41.0 & 20.7 \\
\hline & 2008 & 21 & 41.5 & 21.0 \\
\hline & 2009 & 22 & 41.6 & 21.0 \\
\hline & 2010 & 23 & 44.5 & 22.5 \\
\hline & 2011 & 24 & 45.4 & 22.9 \\
\hline & 2012 & 25 & 47.2 & 23.8 \\
\hline & 2013 & 26 & 48.9 & 24.7 \\
\hline
\end{tabular}

The volume of sediments deposited in reservoir at Krempna before dredging (Krempna-1) and after dredging (Krempna-2) was presented in Table 4. 
Table 4. Volume of deposited sediment and the silting rate of Krempna reservoir.

\begin{tabular}{ccccc}
\hline Reservoir Krempna & Year & Years of Operation & $\begin{array}{c}\text { Volume of Deposited } \\
\left.\text { Sediment } \mathbf{( 1 0}^{\mathbf{3}} \mathbf{~ m}^{\mathbf{3}}\right)\end{array}$ & Silting Ratio S (\%) \\
\hline Before Dredging & 1986 & 14 & 35.7 & 30.0 \\
\hline & 1996 & 9 & 27.0 & 24.1 \\
& 1997 & 10 & 30.5 & 27.2 \\
\multirow{3}{*}{ After Dredging } & 1998 & 11 & 34.6 & 30.9 \\
& 1999 & 12 & 38.0 & 33.9 \\
& 2000 & 13 & 40.1 & 35.8 \\
& 2002 & 15 & 44.2 & 39.5 \\
& 2003 & 16 & 44.9 & 40.1 \\
& 2005 & 18 & 45.8 & 40.9 \\
\hline
\end{tabular}

\subsection{Determination of the Operating Time}

The correlations of silting rates and operating times, presented in Figures 3 and 4, are respective curves predicting the volume reduction of reservoirs at Zesławice and at Krempna. Before dredging, the Zesławice-1 reservoir's volume (Figure 3 ) will be reduced by $50 \%$, according to the criteria of Pitt and Thompson [4], after 13 years. However, after dredging the silting time of this reservoir will be extended to 30 years of operation. This is due to the construction of the assistant reservoir (Zesławice-2), which captures a part of the incoming sediment. On the other hand, silting of the Zesławice-2 reservoir, equal to $50 \%$, will occur after 79 years of operation. The volume reduction by $80 \%$ - according to Hartung's criterion [3] — will occur after a much longer time period of the reservoirs' operation (Figure 3).

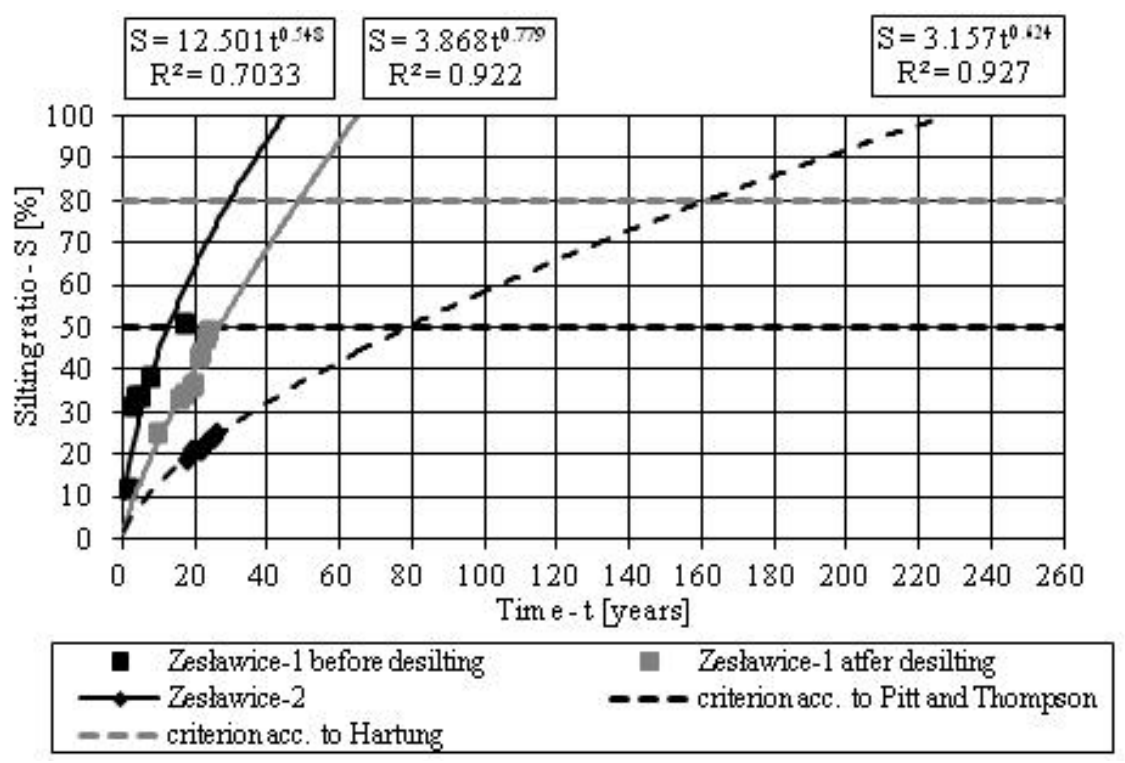

Figure 3. Correlation relationship between the silting rate of reservoirs at Zesławice and their time of operation.

As a consequence of the fact that only one measurement of silting was performed at Krempna reservoir, the correlation between the silting rate and the operating time was not specified. After dredging, eight silting measurements were performed, which were the basis for drawing the curve, thus predicting the 
reduction of the reservoir's volume (Figure 4). Silting of the Krempna reservoir by $50 \%$ after dredging will occur after 21 years of operation.

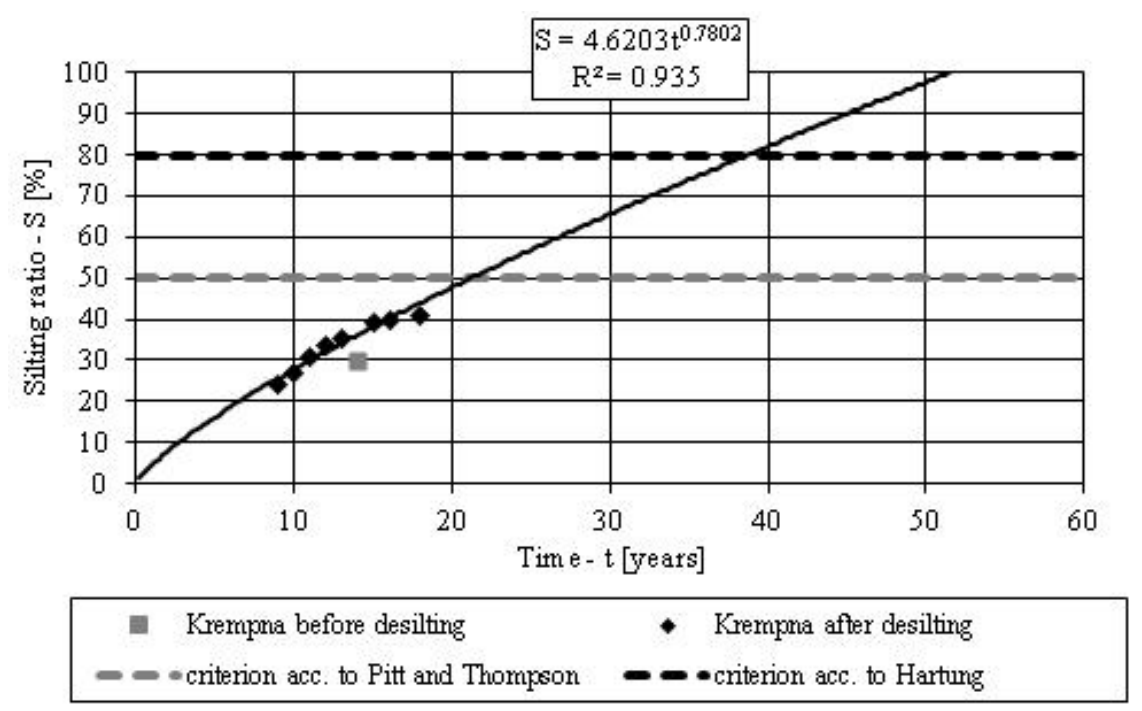

Figure 4. Correlation relationship between the silting rate of reservoir at Krempna and its time of operation.

Before dredging, the Zesławice-1 reservoir was characterized by the highest silting rate, i.e., on average $2.7 \%$ per year. The initial capacity-inflow ratio (C-I ratio) of the main reservoir before dredging was $0.66 \%$. The C-I ratio was determined as the proportion of the reservoir's capacity and the average annual water inflow, while the average annual inflow is $1.09 \mathrm{~m}^{3} \cdot \mathrm{s}^{-1}$. After dredging and redirecting part of water to Zesławice-assistant side reservoir, the average annual water inflow to Zesławice-1 decreased. Due to the separation of water into two reservoirs, the average annual water inflow to the reservoir Zesławice-1 is $0.71 \mathrm{~m}^{3} \cdot \mathrm{s}^{-1}$ and in the reservoir Zesławice-2 it is equal to $0.38 \mathrm{~m}^{3} \cdot \mathrm{s}^{-1}$. In such conditions, with an increase of initial capacity-inflow ratio to $1.02 \%$, the intensity of silting in Zesławice-1 reservoir decreased, which is suggested by the average annual silting rate of this reservoir after dredging- $2.1 \%$ (Table 1). The lowest silting rate, i.e., on average $1.0 \%$ per year, is observed in the side reservoir Zesławice-2. The initial capacity-inflow ratio of this reservoir is $1.65 \%$.

The determined silting intensity of the examined reservoirs, amounting to an average annual of $1.0 \%-2.7 \%$ is higher than the average annual silting rate of small water reservoirs recorded in Great Britain. As reported by Vincent et al. [28], the average annual silting rate of small water reservoirs in Great Britain, determined based on the analysis of 123 reservoirs, is only $0.13 \%$. Much more diverse values were reported by the researchers in the United States. The average annual value of silting of the water reservoir Chili Bar [29], with a capacity of 1.25 million $\mathrm{m}^{3}$, calculated based on 40 years of observations, reached $0.8 \%$. On the other hand, according to Reed and Hoffman [30], the average annual silting rate ranges from $0.57 \%$ to $2.43 \%$. The results obtained in this study are similar to those provided by Reed and Hoffman for the reservoirs in the United States and are also close to the values characteristic of the reservoirs from the East Africa region. According to Haregeweyn et al. [31], the annual total capacity loss values ranged between $0.18 \%$ and $4 \%$ for 13 reservoirs in northern Ethiopia. Similar studies carried out by the Department For International Development [32] reported silting rates ranging between $1 \%$ and $3 \%$ in Zimbabwe and $1 \%$ and $4 \%$ in Tanzania. The data given above indicate that the problem of 
silting intensity of small water reservoirs affects many parts of the world. One way to reduce the silting intensity of small reservoirs may be the application of residuum lodges on feeder streams immediately before the reservoir entrance. Such solution requires frequent dredging of the residuum lodges. Kay et al. [33] estimated that the cleared residuum lodge in reservoir with $974 \times 10^{3} \mathrm{~m}^{3}$ storage capacity would take 12 years to refill. The silting rate may be also reduced by appropriate shaping of the reservoir basin, which may contribute to the reduction in the sediment trap efficiency, thus reducing the sediment deposition in the reservoir. This was evidenced by Dufresne et al. [34] in their experimental studies, analyzing flow patterns and sediment deposition in rectangular shallow reservoirs.

Determination of the coefficients of correlation equations (Figure 3 and 4), being a descriptive measure of regression model fitness to data, indicates strong and very strong data correlation. Therefore, it may be concluded that the silting measurement error does not significantly affect the results. The above examples indicate that the so-called long duration operation cannot be unambiguously determined by using a specific range of years of operation. This parameter needs to be determined using the silting rate. The determination of small reservoirs' silting rate, indicating the so-called long duration operation, was enabled by the analyses of dependency between the relative depth $\left(\mathrm{h}_{\mathrm{i}} / \mathrm{H}\right)$ and the relative volume $\left(V_{i} / V\right)$, developed based on the results of silting measurements and corresponding to different silting rates of the studied reservoirs, that were compared to RDSF curves (Equation (1)).

\subsection{Determination of the Sediment Distribution in the Reservoirs}

A change in water flow conditions at Zesławice-1 reservoir, as a consequence of redirecting part of water and sediment to the side reservoir Zesławice- 2 alters the conditions of transport and sedimentation, and may affect the distribution of sediments in the reservoir, which was demonstrated on the basis of the graphs of the sediment distribution in accordance with the methodology specified by Rahmanian and Banihashemi [17]. The results of calculations of the relative depth $\left(h_{i} / H\right)$ and the relative volume $\left(V_{i} / V\right)$ of Zesławice-1 and Zesławice-2 reservoirs and Relative Depth Shape Function values for different heights from reservoir bed are presented in Tables 5 and 6.

Table 5. Relative Depth Shape Function for different elevations from reservoir bed established for Zesławice-1 reservoir.

\begin{tabular}{cccccc}
\hline Elevation $(\mathbf{m}$ a.s.l. $)$ & Sum of Volume $\left(\mathbf{m}^{\mathbf{3}}\right)$ & Relative Depth $\mathbf{h}_{\mathbf{i}} / \mathbf{H}$ & Relative Volume $\mathbf{V}_{\mathbf{i}} / \mathbf{V}$ & $\mathbf{1} / \boldsymbol{\alpha}$ & $\mathbf{R D S F}$ \\
\hline 211.60 & 0 & 0 & 0.00 & 0.00 & 0.00 \\
211.80 & 489 & 0.06 & 0.00 & 17.00 & 0.04 \\
212.20 & 7756 & 0.18 & 0.03 & 5.67 & 0.19 \\
212.60 & 25,237 & 0.29 & 0.11 & 3.40 & 0.38 \\
213.00 & 52,648 & 0.41 & 0.23 & 2.43 & 0.56 \\
213.40 & 86,916 & 0.53 & 0.38 & 1.89 & 0.72 \\
213.80 & 121,680 & 0.65 & 0.53 & 1.55 & 0.82 \\
214.20 & 156,782 & 0.76 & 0.69 & 1.31 & 0.90 \\
214.60 & 192,222 & 0.88 & 0.84 & 1.13 & 0.96 \\
215.00 & 228,000 & 1.00 & 1.00 & 1.00 & 1.00 \\
\hline
\end{tabular}


Table 6. Relative Depth Shape Function for different elevations from reservoir bed established for Zesławice-2 reservoir.

\begin{tabular}{cccccc}
\hline Elevation (m a.s.l.) & Sum of Volume $\left(\mathbf{m}^{\mathbf{3}}\right)$ & Relative Depth $\mathbf{h}_{\mathbf{i}} / \mathbf{H}$ & Relative Volume $\mathbf{V}_{\mathbf{i}} / \mathbf{V}$ & $\mathbf{1} / \boldsymbol{\alpha}$ & RDSF \\
\hline 212.85 & 0 & 0 & 0.00 & 0.00 & 0.00 \\
213.00 & 694 & 0.07 & 0.00 & 14.33 & 0.05 \\
213.20 & 4376 & 0.09 & 0.02 & 6.14 & 0.14 \\
213.40 & 11,153 & 0.26 & 0.06 & 3.91 & 0.22 \\
213.60 & 21,380 & 0.35 & 0.11 & 2.87 & 0.31 \\
213.80 & 35,968 & 0.44 & 0.18 & 2.26 & 0.41 \\
214.00 & 56,814 & 0.53 & 0.29 & 1.87 & 0.54 \\
214.20 & 83,506 & 0.63 & 0.42 & 1.59 & 0.67 \\
214.40 & 111,940 & 0.72 & 0.57 & 1.39 & 0.78 \\
214.60 & 140,373 & 0.81 & 0.71 & 1.23 & 0.87 \\
214.80 & 169,187 & 0.91 & 0.85 & 1.10 & 0.94 \\
215.00 & 198,000 & 1.00 & 1.00 & 1.00 & 1.00 \\
\hline
\end{tabular}

Sediment distributions before and after dredging of Zesławice-1 reservoir are presented in Figure 5, and the sediment distribution at Zesławice-2 reservoir based on the measurements and the curve of the predicted sediment distribution is presented in Figure 6.

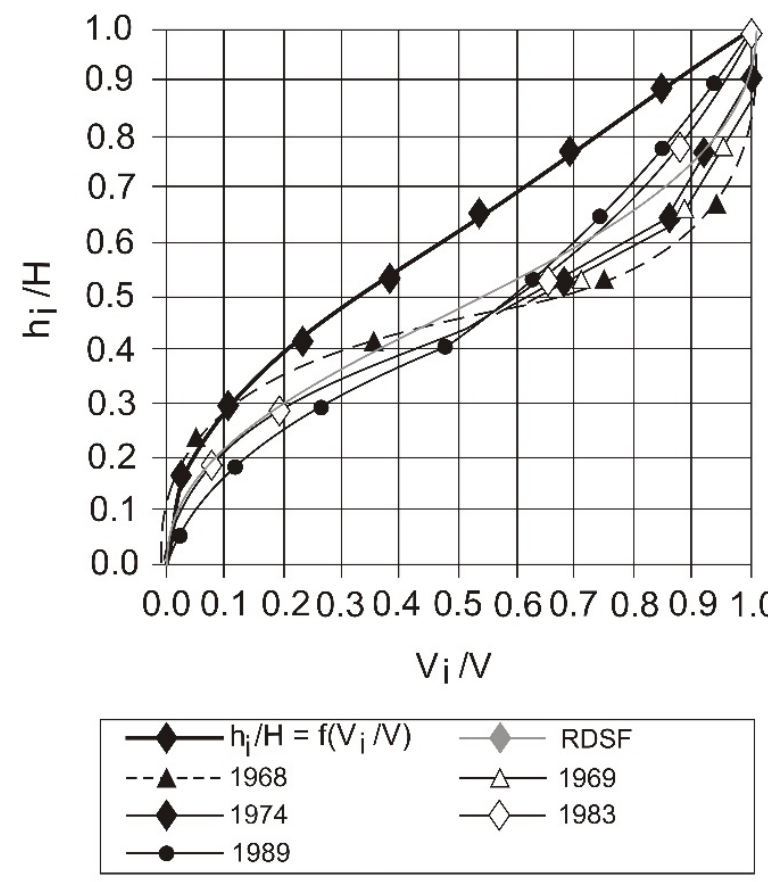

(a)

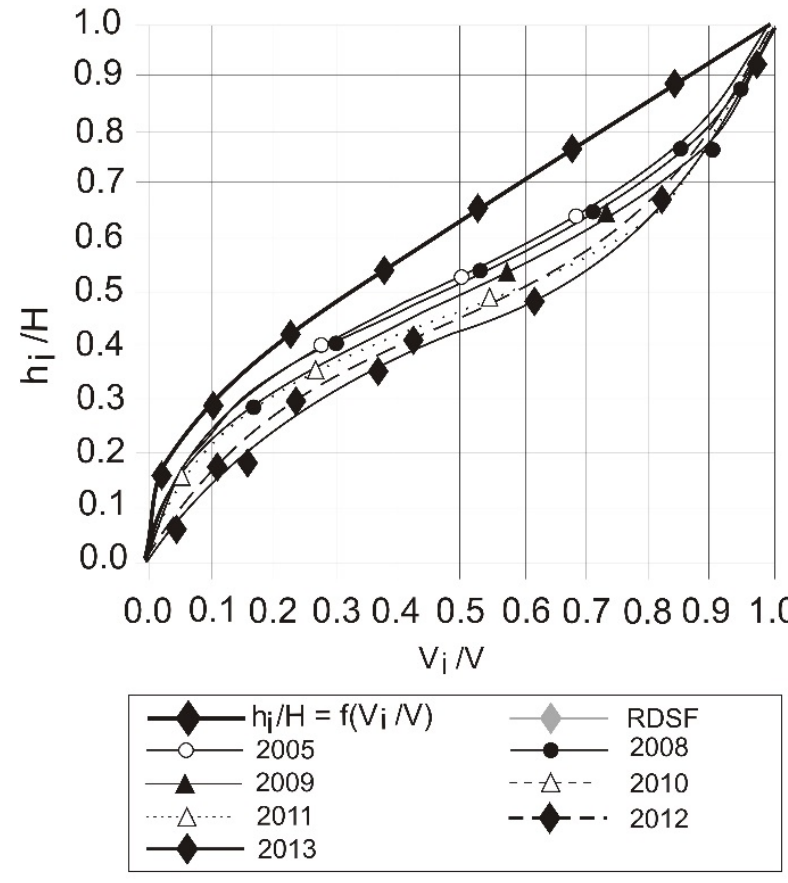

(b)

Figure 5. Comparison of cumulative depth of sediment deposition in reservoir Zesławice-1, described with function $h_{i} / H=f\left(V_{i} / V\right)$, with relative cumulative sediment distribution described according to RDSF parameter; where $h_{i} / H$ is the relative depth, and $V_{i} / V$ is the relative volume, rel. $V$ is the cumulative curve of the reservoir's volume; (a)-reservoir before dredging; (b) — reservoir after dredging. 


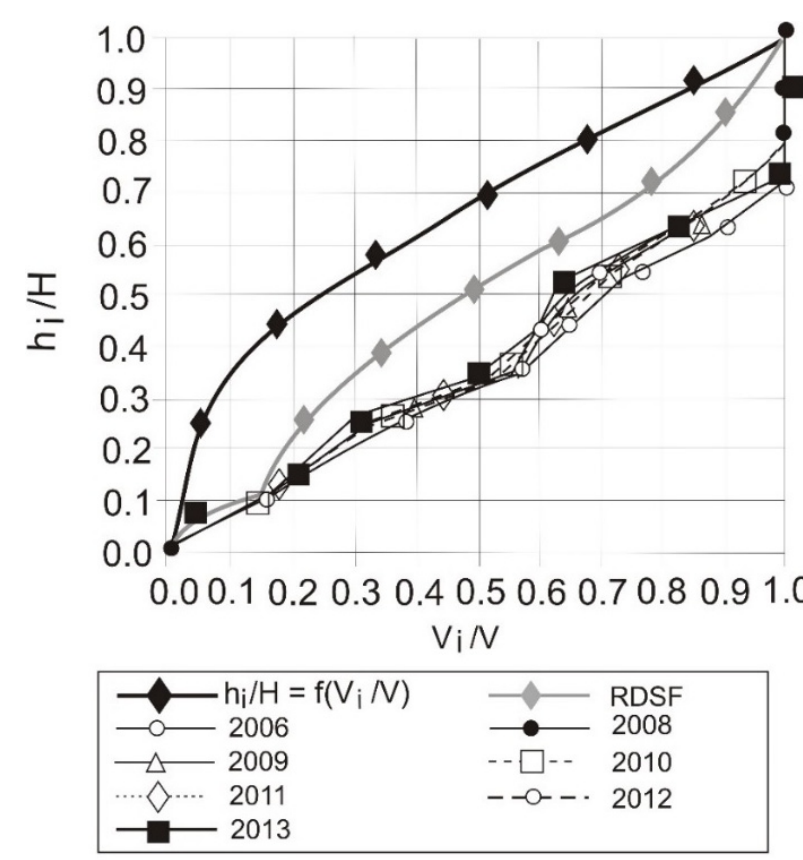

Figure 6. Comparison of cumulative depth of sediment deposition in reservoir Zesławice-2, described with function $h_{i} / H=f\left(V_{i} / V\right)$, with relative cumulative sediment distribution described according to RDSF parameter; where $h_{i} / H$ is the relative depth, $V_{i} / V$ is the relative volume, and rel. $V$ is the cumulative curve of the reservoir's volume.

In the first years of operation (i.e., in 1968, 1969 and 1974), before dredging of Zesławice-1 reservoir (Figure 5a), sediments were deposited mainly in shallow areas, located near the reservoir inlet. In the near-dam zone, where $\mathrm{h} / \mathrm{H}$ ranges from 0.0 to 0.3 , the amount of deposited sediment is small—cumulative curves of sediment deposits only slightly differed from a cumulative curve of the reservoir's volume (curve $h_{i} / H=f\left(V_{i} / V\right)$ in Figure 5a). In subsequent years, i.e., in 17th and 23rd year of the reservoir's operation (respective curves for 1983 and 1989 in Figure 5a), the sediment distribution was increasingly proportional at each relative depth. The sediment distribution curve determined based on silting measurements in 1989 (Figure 5a) is the most similar to the curve predicting the sediment distribution: the Relative Depth Shape Function for different heights from reservoir bed (Equation (1)). The actual vertical distribution of sediment was based on measurement data corresponding to silting of Zesławice-1 reservoir of over $61 \%$. It was also observed that after dredging of this reservoir (Figure $5 \mathrm{~b}$ ), the sediment distribution is nearly the same as before dredging, i.e., in subsequent years of the operation, the relative volume of sediment depositions increased on shallower relative depths, which correspond to the areas of reservoir's bottom located closer to the dam. However, due to water distribution in a junction, which directs part of water inflow to the side reservoir Zesławice-2, small amount of sediment is deposited in the area closest to the dam. Therefore, the layout of sediment distribution curves in Figure 5b, based on the silting measurements is significantly different from the predicted sediment distribution at the relative depths from 0.0 to 0.5 . The sediment distribution estimated from the latest measurement, performed in 2013, presented in Figure 5b, is significantly consistent with the predicted sediment distribution (grey RDSF line). The results differ on average only by $5 \%$. It should, however, be noted that the change in water flow through this reservoir, resulting from water distribution, not only caused a decrease in the amount of sediment deposited in the near-dam parts of the reservoir (relative depths from 0.0 to 0.5 ), but 
also contributed to the intense sediment deposition in the reservoir inlet. In this zone, sediment deposition formed an island composed of sediments that rise above the water level. Thus, in Figure $5 \mathrm{~b}$ relative sediment volumes for the relative depth of 1.0 range from 0.95 to 0.99 .

Sediment deposition over water surface was also found before dredging of this reservoir - presented by the sediment distribution curve based on the measurements performed in 1989 (Figure 5a). Island-formation from sediments causes discrepancies in predicting the distribution of sediments using the RDSF curve. The sediment distribution in the assistant side reservoir Zesławice-2 (Figure 6), based on the measurements in 2005-2013, indicated the initial stage of reservoir silting. Sediment depositions are relatively evenly distributed in parts of the reservoir corresponding to the relative depths of 0.07-0.81. This means that sediment is not deposited in the deepest zones, i.e., of the relative depths below 0.07 , the near-dam and in the most shallowest zones, of the relative depths over 0.81 , by the reservoir inlet. The sediment distribution, presented in Figure 6, corresponds to relatively small reservoir silting - it ranged from $18.8 \%$ in 2005 to $22.5 \%$ in 2010 (Table 3). One can suppose that in subsequent years of operation sediment will be deposited not only in the aforementioned zones of Zesławice-2 reservoir, but also in more shallow zones (at the reservoir inlet), which will cause the approaching of cumulative depth of sediment deposition curves to the RDSF curve.

The results of calculations of the relative depth $\left(h_{i} / H\right)$ and the relative volume $\left(V_{i} / V\right)$ at Krempna reservoir before and after dredging and Relative Depth Shape Function for different elevations from reservoir bed values are presented in Tables 7 and 8, respectively.

Table 7. Relative Depth Shape Function for different elevations from the reservoir bed for Krempna reservoir before dredging.

\begin{tabular}{cccccc}
\hline Elevation (m a.s.l.) & Sum of Volume $\left(\mathbf{m}^{\mathbf{3}}\right)$ & Relative Depth $\mathbf{h}_{\mathbf{i}} / \mathbf{H}$ & Relative Volume $\mathbf{V}_{\mathbf{i}} / \mathbf{V}$ & $\mathbf{1 / \boldsymbol { \alpha }}$ & $\mathbf{R D S} \boldsymbol{0}$ \\
\hline 366.28 & 70 & 0.00 & 0.00 & 0.00 & 0.00 \\
366.40 & 400 & 0.03 & 0.00 & 31.00 & 0.10 \\
366.80 & 4590 & 0.14 & 0.04 & 7.15 & 0.28 \\
367.20 & 14,570 & 0.25 & 0.12 & 4.04 & 0.49 \\
367.60 & 26,480 & 0.35 & 0.22 & 2.82 & 0.63 \\
368.00 & 38,520 & 0.46 & 0.32 & 2.16 & 0.70 \\
368.40 & 51,860 & 0.57 & 0.44 & 1.75 & 0.76 \\
368.80 & 67,590 & 0.68 & 0.57 & 1.48 & 0.84 \\
369.20 & 84,570 & 0.78 & 0.71 & 1.27 & 0.90 \\
369.60 & 101,680 & 0.89 & 0.85 & 1.12 & 0.96 \\
370.00 & 119,100 & 1.00 & 1.00 & 1.00 & 1.00 \\
\hline
\end{tabular}

Before dredging of Krempna reservoir (Figure 7a) in the 14th year of operation, sediment deposition in the deepest part of the reservoir (relative depths from 0.0 to 0.6 ) is similar to the one described by the RDSF curve. Smaller amounts of sediments are deposited at inlet zones with relative depths from 0.6 to 1.0 - the sediment distribution curve deviates significantly from the one predicted with the RDSF curve. The sediment distribution, presented in Figure 7 a has been determined for a 30\% silting rate. As shown in Figure $7 b$, at higher silting rate, the sediment distribution layout approaches the RDSF curve. After dredging of the Krempna reservoir, the discrepancy between sediment distribution curves and RSFD curve in the deepest part of the reservoir (relative depths from 0.0 to 0.6 ) increases for higher silting rates. 
Table 8. Relative Depth Shape Function for different elevations from the reservoir bed for Krempna reservoir after dredging.

\begin{tabular}{cccccc}
\hline Elevation $(\boldsymbol{m}$ a.s.l.) & Sum of Volume $\left(\mathbf{m}^{\mathbf{3}}\right)$ & Relative Depth $\mathbf{h}_{\mathbf{i}} / \mathbf{H}$ & Relative Volume $\mathbf{V}_{\mathbf{i}} / \mathbf{V}$ & $\mathbf{1} / \boldsymbol{\alpha}$ & $\mathbf{R D S F}$ \\
\hline 366.50 & 50 & 0.00 & 0.00 & 0.00 & 0.00 \\
366.80 & 860 & 0.09 & 0.01 & 11.67 & 0.09 \\
367.20 & 4420 & 0.20 & 0.04 & 5.00 & 0.20 \\
367.60 & 13,200 & 0.31 & 0.12 & 3.18 & 0.37 \\
368.00 & 27,500 & 0.43 & 0.25 & 2.33 & 0.57 \\
368.40 & 43,060 & 0.54 & 0.38 & 1.84 & 0.71 \\
368.80 & 60,010 & 0.66 & 0.54 & 1.52 & 0.82 \\
369.20 & 77,220 & 0.77 & 0.69 & 1.30 & 0.89 \\
369.60 & 94,540 & 0.89 & 0.84 & 1.13 & 0.95 \\
370.00 & 112,000 & 1.00 & 1.00 & 1.00 & 1.00 \\
\hline
\end{tabular}

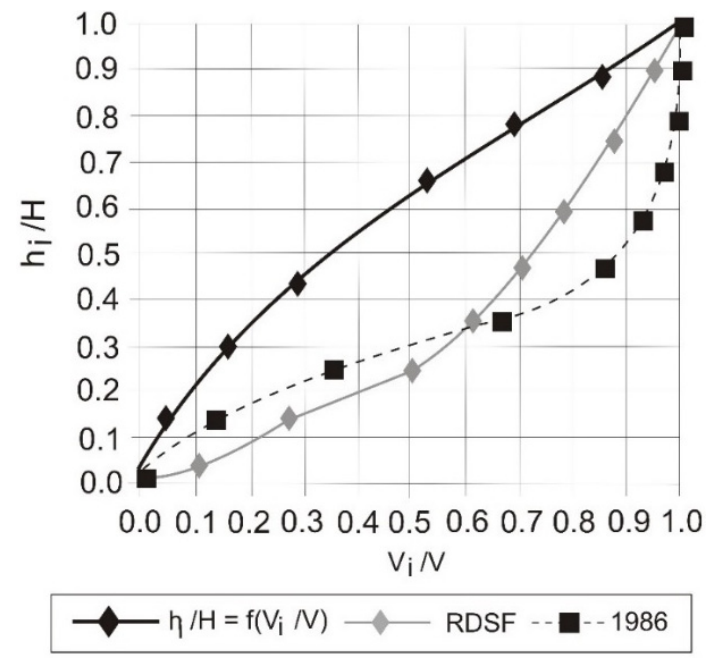

(a)

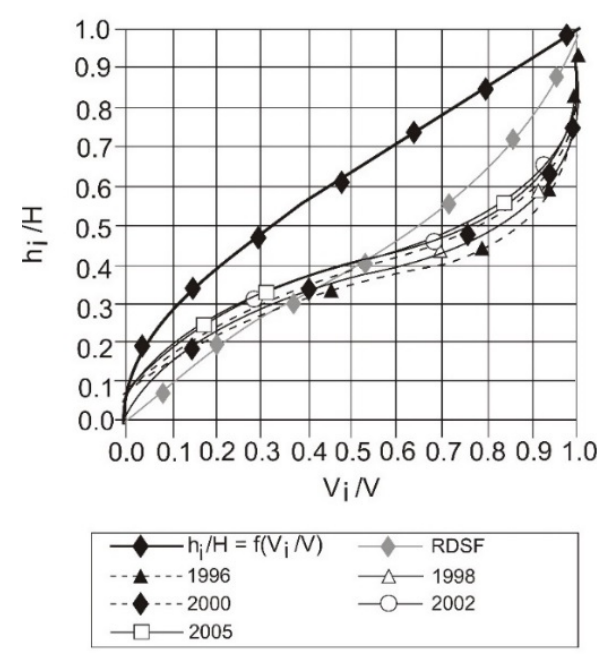

(b)

Figure 7. Comparison of cumulative depth of sediment deposition in Krempna reservoir, described with function $h_{i} / H=f\left(V_{i} / V\right)$, with relative cumulative sediment distribution calculated according to Relative Depth Shape Function (RDSF) parameter; where $h_{i} / H$ is the relative depth, $V_{i} / V$ is the relative volume, and rel. $V$ is the cumulative curve of the reservoir's volume; (a) — reservoir before dredging; (b) — reservoir after dredging.

In 1996, i.e., in the ninth year of operation, the silting rate of Krempna reservoir was $24.1 \%$ - there was the greatest difference between the sediment distribution (Figure 7a) and the forecast of distribution according to the RDSF curve. In 2005, i.e., in the 18th year of operation, the silting rate was less than $41 \%$ - the sediment distribution curve (Figure 7b) was the most similar to the RDSF curve. It may be assumed that, after the reservoir is silted by 50\%, which, according to criteria of Pitt and Thompson [4], restricts the reservoir's operational conditions, the actual sediment deposition will be similar to the one described by the RDSF curve.

\section{Conclusions}

The examined small reservoirs at Zesławice and Krempna are characterized by high intensity of silting. The calculated average annual silting rate of the examined reservoirs falls within the range of 
$1.0 \%-2.7 \%$ and the time of operation, after which the reservoirs will be silted by $50 \%$, according to the criterion of Pitt and Thompson [4] determined based on the correlation dependencies (Figures 3 and 4), reaches several dozen or even several years. Therefore, the determination of long duration operation period, after which we will obtain the results of calculations forecasting the sediment distribution by using Rahmanian's and Banihashemi's method, corresponding to the actual distribution, should be made more specific. The long duration operation is a time when the silting rate reaches $50 \%$.

In the first years of operation, the investigated sediments were deposited mainly in shallow areas, located near the reservoir inlet. In subsequent years, the sediment distribution was increasingly proportional at each relative depth. When silting ratio increase then sediment distribution curve is the most similar to the curve predicting the sediment distribution: the Relative Depth Shape Function for different heights from reservoir bed. It may be assumed that, after the investigated small reservoirs are silted by $50 \%$, which, according to criteria of Pitt and Thompson [4], restricts the reservoir's operational conditions, the actual sediment deposition will be similar to the one described by the RDSF curve. However island-formation from sediments causes discrepancies in predicting the distribution of sediments using the RDSF curve.

The rapid silting of investigated small reservoirs allowed to analyzing changes in the silting rate and the sediment distribution in subsequent years of operation. One can assume that the silting rate of a small reservoir reaches $20 \%-30 \%$, the actual sediment distribution is similar to the one described by the Relative Depth Shape Function (RDSF) curve and the curves of cumulative depth of sediment deposition, described with function $h_{i} / H=f\left(V_{i} / V\right)$ are increasingly convergent to the RDSF curve for increasingly higher degrees of silting.

The forecast of vertical distribution of sediments in small reservoirs with a volume of less than $5 \times 10^{6} \mathrm{~m}^{3}$ and the capacity-inflow ratio less than $10 \%$, may be developed using the method of Rahmanian and Banihashemi [17], assuming that the so-called long duration operation is achieved when the degree of reservoir silting is $50 \%$.

\section{Acknowledgments}

Funding was provided by the Faculty of Environmental Engineering and Land Surveying at the University of Agriculture in Cracow (Poland). This study has been financially supported by program DS-3322/KIWiG.

\section{Conflicts of Interest}

The author declares no conflict of interest.

\section{References}

1. Michalec, B. Appraisal of silting intensity of small water reservoirs in the Upper Vistula river basin. In Scientific Fascicles; Agricultural University Cracow: Kraków, Poland, 2008; p. 193. (In Polish)

2. Haregeweyn, N.; Melesse, B.; Tsunekawa, A.; Tsubo, M.; Meshesha, D.; Balana, B.B. Reservoir sedimentation and its mitigating strategies: A case study of Angereb reservoir (NW Ethiopia). J. Soils Sediments 2012, 12, 291-305. 
3. Hartung, F. Ursache und Verhuetung der Staumraumverlandung bei Talsperren. Wasserwirtschaft 1959, 1, 3-13.

4. Pitt, J.D.; Thompson, G. The impact of sediment on reservoir life. In Challenges in African Hydrology and Water Resources, Proceeding of the Harare Symposium, Harare, Zimbabwe, July 1984; IAHS: Wallingford, Oxfordshire, 1984; Volume 144, pp. 541-548.

5. Michalec, B. The Use of Modified Annandale's Method in the Estimation of the Sediment Distribution in Small Reservoirs-A Case Study. Water 2014, 6, 2993-3011.

6. Program of Small Retention of the Małopolski District; Project of Marshal Office of Małopolski District and Land Melioration and Water Units Board of Małopolski Province in Cracow: Cracow, Poland, 2004; p. 47. (In Polish)

7. Batuca, G.D.; Jordaan, M.J., Jr. Silting and Desilting of Reservoirs; A.A.Balkema: Rotterdam, The Netherlands, 2000; pp. 1-358.

8. Borland, W.M.; Miller, C.R. Distribution of sediment in large reservoirs. J. Hydraul. Eng. Div. ASCE 1958, 84, 1-18.

9. Lara, J.M. Revision of the Procedure to Compute Sediment Distribution in Large Reservoirs; U.S. Bureau of Reclamation: Denver, CO, USA, 1962.

10. Strand R.I.; Pemberton, E.L. Reservoir Sedimentation Technical Guidelines for Bureau of Reclamation; U.S. Bureau of Reclamation: Denver, CO, USA, 1982; p. 48.

11. Szechowycz, R.W.; Qureshi, M.M. Reservoir Sedimentation; Technical Guideline for Bureau of Reclamation: Denver, CO, USA, 1973.

12. Borland, W.M. Reservoir sedimentation, river mechanics. Water Resour. 1970, 29, 1-38.

13. Garde, R.J.; Swamee, P.K.; Dalvi, M.E. Estimation of progressive deposition in reservoirs. In Proceeding of the 47th Research Session of the CBIP, Hubli-Dharwar, Karnataka, 1978; Volume 1, pp. 1-50.

14. Croley, T.E.; Raja Roa, K.N.; Karim, F. Reservoir Sedimentation Model with Continuing Distribution, Compaction and Slump; Iowa Institute of Hydraulic Research (IIHR) Report no.198; The University of Iowa: Iowa City, IA, USA, 1978.

15. Rooseboom, A.; Annandale, G.W. Reservoir sedimentation and stream power. In Proceeding of the D.B. Simons Symposium on Erosion and Sedimentation, Colorado State University, Fort Collins, CO, USA, 1983; p. 20.

16. Annandale, G.W. Predicting the distribution of deposited sediment in southern African reservoirs. In Challenges in African Hydrology and Water Resources, Proceedings of the Harare Symposium, Harare, Zimbabwe, July 1984; IAHS: Wallingford, Oxfordshire, 1984; Volume 144, pp. 549-558.

17. Rahmanian, M.R.; Banihashemi, M.A. Introduction of a new empirical reservoir shape function to define sediment distribution pattern in dam reservoirs. IJST Trans. Civil Eng. 2012, 36, 79-92.

18. Lara, J.M.; Pemberton, E.L. Initial weight of deposited sediments. In Proceeding of the Federal Interagency Sedimentation Conference, Jackson, MS, USA, 28 January-1 February 1963; USDA-ARS, Miscellaneous Publications: Jackson, MS, USA, 1963; Volume 970, pp. 818-845.

19. Water-Law Report for Water Damming and Retention; Zesławice reservoir on the river Dłubnia, Archives of the Cracow Association of Water Companies: Cracow, Poland, 2003. (In Polish)

20. Dalgaard, P. Introductory Statistics with R. Statistics and Computing, 2nd ed.; Springer: New York, NY, USA, 2008; p. 364. 
21. Piyawat, W.; Mukand, S.B. Principal Component and Multiple Regression Analyses for the Estimation of Suspended Sediment Yield in Ungauged Basins of Northern Thailand. Water 2014, 6, 2412-2435.

22. Romero-Díaz, A.; Alonso-Sarriá, F.; Martínez-Lloris, M. Erosion rates obtained from check-dam sedimentation (SE Spain). A multi-method comparison. Catena 2007, 71, 172-178.

23. Neto, I.E.L.; Wiegand, M.C.; de Araújo, J.C. Sediment redistribution due to a dense reservoir network in a large semi-arid Brazilian basin. Hydrol. Sci. J. 2011, 56, 319-333.

24. Jebari, S.; Berndtsson, R.; Bahri, A.; Boufaroua, M. Spatial soil loss risk and reservoir siltation in semi-arid Tunisia. Hydrol. Sci. J. 2010, 55, 121-137.

25. Rausch, D.L.; Heinemann, H.G. Measurement of reservoir sedimentation. In Erosion and Sediment Yield: Some Methods of Measurement and Modeling; Geobooks: Norwich, UK, 1984; pp. 179-200.

26. Bednarczyk, T.; Lubowiecka, T. Silting of small water reservoirs. In Proceeding of the Conference on Transport and Sedimentation of Soild Particles (Prague); Technical University: Prague, Czech Republic, 1995; pp. C2:1-C2:7.

27. Montgomery, D.C.; Runger, G.R.; Hubele, N.F. Engineering Statistics, 5th ed.; Wiley Global Education: Hoboken, NJ, USA, 2010; pp. 1-544.

28. Vincent, R.; Dębski, D.; Green, T. Department of Environment, Transport and the Regions. In Sedimentation in Storage Reservoirs; Final Report; Halcrow Water: Burderop Park, Swindon, Wiltshire, 2001; p. 167.

29. Tarbell, D. Chili Bar Reservoir Sediment Deposition Technical Report; Sacramento Municipal Utility District Sacramento, California and Pacific Gas and Electric Company: San Francisco, CA, USA, 2004; p. 35.

30. Reed, L.A.; Hoffman, S.A. Sediment Deposition in Lake Clarke, Lake Aldred and Conowingo Reservoir. Pennsylvania and Maryland, 1910-93; Water-Resources Investigations Report 96-4048; U.S. Geological Survey: Lemoyne, PA, USA, 1997; p. 14.

31. Haregeweyn, N.; Poesen, J.; Nyssen, J.; de Wit, J.; Haile, H.; Gover, G.; Deckers, J. Reservoirs in Tigray: Characteristics and sediment deposition problems. Land Degrad. Dev. 2006, 17, 211-230.

32. Department for International Developmen (DFID). Guidelines for Predicting and Minimizing Sedimentation in Small Dams; HR Wallingford Ltd.: Wallingford, UK, 2004; pp. 1-120.

33. Kay, P.; Armstrong, A.; McDonald, A.; Parsons, D.; Best, J.; Peakall, J.; Walker, A.; Foulger, M.; Gledhill, S.; Tillotson, M. A pilot study of the efficacy of residuum lodges for managing sediment delivery to impoundment reservoirs. Water Environ. J. 2009, 23, 52-62.

34. Dufresne, M.; Dewals, B.; Erpicum, S.; Archambeau, P.; Pirotton, M. Flow patterns and sediment deposition in rectangular shallow reservoirs. Water Environ. J. 2012, 26, 504-510.

(C) 2015 by the authors; licensee MDPI, Basel, Switzerland. This article is an open access article distributed under the terms and conditions of the Creative Commons Attribution license (http://creativecommons.org/licenses/by/4.0/). 